\title{
Staphylococcus aureus (MRSA and CA-MRSA strains) in South America: comparative review to emergence of strains in North America and worldwide
}

\section{Staphylococcus aureus (cepas MRSA e CA-MRSA) na América do Sul: revisão comparativa com emergência de cepas na América do Norte e no mundo}

\author{
Andre Leonardo Nogueira Farias ${ }^{1}$. Cristiane Cunha Frota ${ }^{2}$. \\ 1 Acadêmico de Medicina da Universidade Federal do Ceará (UFC), Fortaleza, Ceará, Brasil e Intercambista em Microbiologia \\ Geral e Imunologia Humana na Universidade de Liverpool (UoL), Liverpool, Reino Unido (2015). 2 Professora Associada de \\ Microbiologia do Departamento de Patologia e Medicina Legal, Faculdade de Medicina, Universidade Federal do Ceará (UFC), \\ Fortaleza, Ceará, Brasil. PhD em Microbactérias pela University College London - National Institute for Medical Research, \\ Londres, Reino Unido (2002).
}

\begin{abstract}
Background: In the last few years, 3 different strains of MRSA have emerged: Community-associated Methicillin-resistant $S$. aureus (CA-MRSA), Hospital-associated (HA-MRSA), and Livestock-associated (LA-MRSA). The most common CA-MRSA strain is USA 300 lineage. In Brasil, this superbacteria is an important public health problem, once they are associated with severe infections (sepsis, shock and osteomyelitis), high mortality rates (including babies) and low response to usual treatments. Aim: To review attempts to compare CA-MRSA strains in South America and propose an interconnection with patterns of North America and worldwide strains. Methods: Non-systematic review. Findings: Epidemiological and Genotyping definitions were used to compare different strains in different continents. Thus, we could determine ST30 $0^{+}$as the most common lineage in the Brazil and South America, USA 300 lineage as the most common in North America and ST80 as the most common in Europe. Conclusion: MRSA is a seriously public health problem in Brazil and worldwide. In few years scientist will need a better understand of bacteria-derived factors that participate in enhanced MRSA pathogenesis \& host susceptibility. Also, scientists will need to improve tools for an early diagnosis and they will need to enhance preventative/therapeutic modalities. However, new challenges will keep emerging.
\end{abstract}

Keywords: Staphylococcus aureus. Methicillin-resistant Staphylococcus aureus. Superinfection. Drug resistance.

\section{RESUMO}

Introdução: Nos últimos anos, emergiram três diferentes cepas de Staphylococcus aureus resistentes à meticilina (MRSA): Adquirida na Comunidade (CA-MRSA), Adquirida em Hospitais (HA-MRSA) e Adquirida na Pecuária (LA-MRSA). A cepa mais comum de CA-MRSA é a linhagem USA 300. No Brasil, essas superbactérias são um importante problema de saúde pública, uma vez que eles estão associados com infecções graves (sepse, choque e osteomielite), altas taxas de mortalidade (incluindo mortalidade neonatal) e baixa resposta aos tratamentos usuais. Objetivo: Revisar as tentativas de comparação das cepas de CAMRSA na América do Sul e propor uma interconexão com padrões de ocorrência de cepas na América do Norte e mundialmente. Métodos: Revisão não sistemática. Resultados: Definições epidemiológicas e de genotipagem foram usadas para comparar diferentes cepas nos diferentes continentes. Determinamos que a linhagem ST30 foi a mais comum no Brasil e na America do Sul, a USA 300 como a mais comum na America do Norte e a linhagem ST80+ como a mais comum na Europa. Conclusão: A emergência de MRSA é um problema de saúde pública no Brasil e no mundo. Num futuro próximo, os pesquisadores necessitarão de um melhor entendimento dos fatores bacterianos envolvidos na patogênese do MRSA e no aumento da suscetibilidade do hospedeiro. Será necessário otimizar os instrumentos para o diagnóstico precoce, bem como as modalidades de prevenção e os métodos de tratamento. No entanto, novos desafios continuarão emergindo.

Palavras-chave: Staphylococcus aureus. Staphylococcus aureus resistente a meticilina. Superinfecção.Resistência a medicamentos. Corresponding Author: Cristiane Cunha Frota, Rua Monsenhor Furtado s/n, Rodolfo Teófilo, Fortaleza, Ceará. Telefone: +5585 3366-8300. CEP: 60441-750. E-mail: cristianefrota71@gmail.com

Conflict of interests: The authors have no conflicts of interest to declare.

Received: 27 Out 2015; Revised: 07 Dec 2015; Accepted: 14 Dec 2015. 


\section{INTRODUCTION}

Staphylococcus aureus is a Gram-positive bacteria and it is a pore-forming toxic molecule producer. The leading cause of human bacterial infections worldwide usually lives as a commensal organism in humans and it affects asymptomatically $1 / 3$ of human population. Nostrils are the most common colonization site, but there are known extra-nasal sites (e.g. throat, axilla, groin, perirectal area). Colonization sites are commonly related with subsequent infections. ${ }^{1-3}$

Transmission occurs via direct contact with the organism, in other words, skin-to-skin contact with colonised or infected individuals. Fomites and sexual transmission are other possible ways to get infected. The main predisposing risk factors are skin trauma, infection drug use, and poor personal hygiene. According to $\mathrm{CDC}$, there are 5C-risk factors: crowding, contact, contaminated, compromised, and cleanliness. ${ }^{1,2}$

Symptoms varies widely in severity. The most common is skin and soft tissue infections (SSTI) - abscesses and cellulitis responsible for around $90 \%$ of the worldwide cases. Invasive infections can cause bacteraemia, leading to complex cases and syndromes (e.g. Purpura fulminans, Myositis, Necrotising fasciitis, Osteomyelitis, Necrotizing pneumonia and Endocarditis). ${ }^{1,2}$

Diagnosis is mainly based in culture from blood, tissue or pus. The exam has a high specificity, thus a culture failure is a strong evidence against $S$. aureus infection. Antimicrobial susceptibility can also be tested, but it does not discriminate differences between strains. It is important to highlight that selection of the appropriate treatment for infection requires antibiotic susceptibility patterns plus a careful assessment of patients' history. ${ }^{1,2}$

S. aureus was first described in 1881 by Sir Alexander Ogston, when the infection was usually fatal because the lack of antibiotics. ${ }^{3}$ The beginning of a new age started with the discovery of Penicillin by Alexander Fleming in 1928. Previously untreatable infectious disease as $S$. aureus infection became treatable. Although, scientists and doctor's happiness did not last for a long time, once antibiotic resistance started to be descripted.

Staphylococcus became resistant to sulfonamide in 1940s. In 1944, it became resistant to Penicillin (PRSA) by direct inactivation of the drug. In 1960s, it finally became resistant to Methicillin (MRSA) by acquisition of an alternative penicillinbinding protein (PBP-2) with lowered affinity to B-lactam., ${ }^{1,2}$

In the past 60 years, MRSA strains started an age of antibiotic resistance epidemic. Normally associated with nosocomial infections, besides this notion has changed greatly in the past few years. MRSA is among the leading causes of death by one single infectious agent, causing more deaths annually than HIV/AIDS in the USA. ${ }^{1-3}$

In the last 20 years, MRSA became hyper-virulent. Thus, it became multidrug resistant. The pandemic clones ST5, ST8,
ST22, ST30, and ST45 are nowadays one of the most seriously health problems worldwide..$^{1-3}$

\section{DEFINITION \& HISTORY: CA-MRSA, HA-MRSA \& LA- MRSA}

The discovery of Community-associated Methicillin-resistant $S$. aureus (CA-MRSA) occurred in 1990s, attributed to paediatric cases in the Midwestern United States. However, there are older description in cases associated with IV drug user in Detroit, MI, and Aboriginal populations in Western Australia (WA-1) - both strains were subsequently classified as MLST clonal complex (CC) 1 (Figure 1). ${ }^{4}$

Figure 1. Definitions: CA-MRSA, HA-MRSA and LA-MRSA.

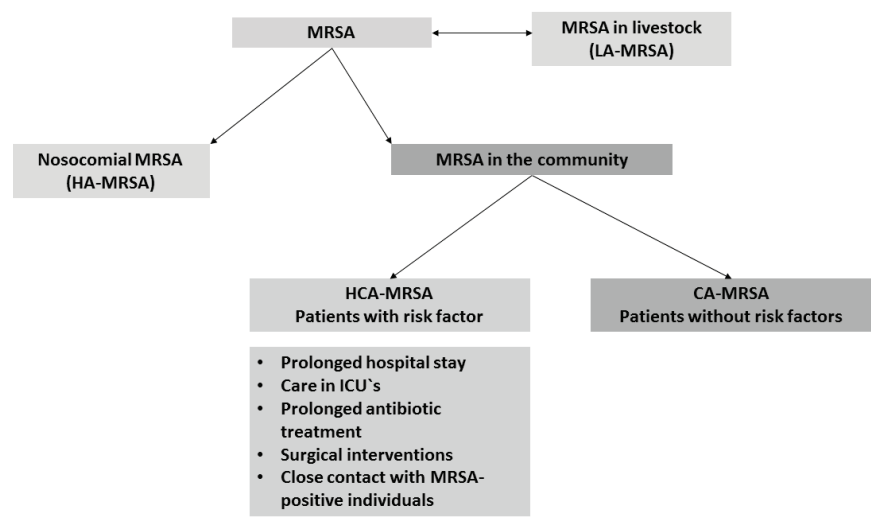

Source: Prepared by the author.

In 2000, a different lineage emerged CC8 or "USA300". The latter quickly eclipsed MW2 (USA400), becoming the primary cause of skin and soft tissue infections (SSTI) in the US, and greatly increasing the burden of community MRSA carriage and transmission. During the same period, genetically distinct CA lineages were reported from numerous countries. ${ }^{4}$

In the last few years CA-MRSA became a health problem worldwide. For instance, in the period of 2000-2003, it was responsible for more than $50 \%$ of USA infections while in France it was responsible for just $1-3 \%{ }^{1-3}$

According to CDC, CA-MRSA is a disease contracted within 48 hours of hospital admission by patients not having recently undergone surgery, haemodialysis, and prolonged hospitalization. Meanwhile, this is an epidemiological definition and it has lots of misclassifications, once CA-MRSA is an increasing cause of health care-acquired infections. ${ }^{1-3}$

CA-MRSA is traditionally regarded as MRSA strains causing infection (cellulitis or abscesses) in previously healthy young patients without prior healthcare contact, susceptible to most non- $\beta$-lactam antimicrobial agents, and carrying Panton Valentine (PVL) genes and SCCmec types IV and V. ${ }^{1-3}$

On the other hand, Hospital-associated Methicillin-resistant 
S. aureus (HA-MRSA) is related to MRSA strains causing infections (bacteraemia) in patients with prolonged hospital stay, care in ICU's, prolonged antibiotic treatment, surgical infections, close contact with MRSA-positive individuals. They are usually related with risk groups of population or risk factors: history of colonization/infection with $\mathrm{CA}$, close contact (family) with a person colonized/ infected with CA, membership of an indigenous community; being member of special communities (participation in contact sports, injection drug use, living in correctional facilities or shelters, military personnel, and men who have sex with men). HA-MRSA is less virulent than CA-MRSA. . $^{1,2,5}$

Livestock-associated Methicillin-resistant S. aureus (LAMRSA) or CC398 (most common strain) is related to MRSA in animals. It is widely disseminated among pigs in European countries with high-density pig farming (The Netherlands, Denmark and Germany), but it also affects veal calves, horse and dogs. The main concern about those strains is a possible adaptation to human, as already related in some Chinese Hospitals. Thus, animals will be an endless reservoir of infection. ${ }^{1,2,6}$

\section{VIRULENCE}

S. aureus genome structure has 3 principal components: backbone of core genes, dispersed core of variable genes, and mobile genetic elements. The backbone of core genes is founded in all strains and they are highly conserved. Core variable genes $(\mathrm{CV})$ are dispersed through the backbone composing a high variable group. MGE are constantly transferred and they are especially related to acquisition of PBP-2, an alternative penicillin-binding protein encoded by mecA and harboured in a genetic element: Staphylococcal cassete chromosome (SCCmec) that encodes resistance to methicillin. Depending on the particular SCCmec type, these mobile islands can confer multidrug-resistance. ${ }^{1,7-10}$

MRSA defence is based in 2 mains strategies: Immune evasion and Virulence factors. The main components related to Immune evasion are: cytotoxins, immunomodulatory proteins, protease and factors that prevent immune cell recognition and killing (protein $\mathrm{A} /$ capsule/ catalase). On the other hand, virulence factors are divided in 3 main groups: surface proteins, enzymes and secreted toxins. , $^{1,-10}$

\section{Virulence factors}

\section{Panton-Valentine Leucocidin (PVL)}

Leucocidins are molecules transferred via Mobile Genetic Elements that attack and lyses neutrophils (main cell involved in pathogenesis of infection associated with $S$. aureus). Leucocidin remain as the forefront of pathogenesis research initiatives. . $^{1,9,10}$

Panton-Valentine leucocidin is a bicomponent pore-forming toxin located in prophage phiSA2pvl and encoded in genes lukS-PV and lukF-PV, responsible for induce necrosis and apoptosis in leukocytes by binding to host membranes and forming B-barrel pores that span the phospholipid bilayer. ${ }^{1,9,10}$

\section{Enterotoxins}

High resistant (heat stable and resistant to enzymatic degradation) and variable (more than 20 types) toxins. Enterotoxins activate $\mathrm{T}$ cell population by passing the traditional pathway of MHC-TCR generating an excessive inflammatory response: leading to toxic shock, multi-organ failure and death. Thus, they are commonly related to immunemediated diseases: Kawasaki disease, atopic dermatitis, and chronic rhinosinusitis. ${ }^{1,9,10}$

\section{Spa}

Polymorphism in Protein A coding sequence. ${ }^{3}$

\section{Multilocus sequence type (MLST/ ST) or CC}

Multi-Locus Sequence Typing (MLST) involves the sequencing of fragments from seven "housekeeping" genes (arcC, aroE, glpF, gmk, pta, tpi and yqiL) yielding unique sequence types (STs). STs sharing identity at the majority of these loci are grouped into Clonal Complexes (CCs) encompassing related lineages of MRSA. Scientist discovered most MRSA disease worldwide was caused by five major CCs: CC5, CC8, CC22, CC30 and CC45. ${ }^{3}$

\section{Staphylococcal cassette chromosome (SCCmec)}

There are 8 SCCmec types (I-VIII). The most common is SCCmecIV. SCCmec types could be divided in 2 main groups: SCCmec I-III and SCCmecIV-V. The first group is related to HA-MRSA: large length, little movement and contain additional drug resistance to several classes of antibiotics. The second group is related to CA-MRSA: small length, spread easily, more mobile and drug resistance only to beta-lactam. ${ }^{10}$

\section{Toxins: alfa-toxin \& Phenol-Soluble Toxins (PSM)}

a) Alfa-toxin

Pore-forming toxin and well-stabilised major virulence determinant. It is not lytic to human neutrophils, but lyses other immune cells; promotes an influx of neutrophils to infected lungs and enhance neutrophil adhesion to endothelial cell. ${ }^{1,9,10}$

\section{b) Phenol-soluble modulins (PSM)}

Amphipathic/alpha-helical peptides belonging to surfactantlike class, which responsible for neutrophil lysis and for immune response avoiding. ${ }^{1,9,10}$

\section{Mobile-genetic element (MGE)}

Newly acquired sequence of genes that can move around in genome and transferred between strains by horizontal gene transfer leading to selective advantage. MGE are determinants of colonisation/transmissibility rather than virulence. Examples: bacteriophages encoding toxins, pathogenicity 
and composite islands (SaPIs), plasmids and transposons, $\mathrm{SCCmec}$ SCC (non-mec), genomic islands. They are more prevalent among the USA lineage. Therefore, MGE are one of the possible factors responsible for the success of adaptation of those clones across the globe. ${ }^{1,9,10}$

\section{Arginine-catabolic mobile element (ACME)}

Genetic element acquired by CA-MRSA isolates unique to USA300. Physically linkage of ACME with SCCmec IV is mirrored by an epidemiological linkage. ACME aids primarily in USA300 colonization through the Arc mediated ammonification of the acidic skin environment, though this has never been experimentally verified. ${ }^{3}$

\section{GENOTYPE}

Once epidemiological definitions and classifications are not well accurate, genetic typing methods are the most plausible form of classification. However, there is no single, stable genetic marker for CA-MRSA strains. PVL genes were proposed as markers, but there are variations (positive and negative strains). ${ }^{11,12}$

The most used genotyping methods are: ${ }^{12}$

1. Spa sequence typing: sequence polymorphism in the variable $\mathrm{X}$ region of the spa gene for $S$. aureus surface protein A.
2. Multilocus sequence typing (MLST): sequencing of fragments from seven "housekeeping genes" (arc, aroE, glpF, gmK, pta, tpi yqiL) yielding unique sequence types (ST). ST sharing identity at the majority of these grouped into Clonal Complexes (CC) encompassing related lineages of MRSA. For example, the 5 major types clonal complexes are CC5, CC8, CC22, CC30 and CC45.

3. SCCmec typing (PFGE): MGEs - highly discriminatory approach that can identify genomic rearrangements (insertions/deletions) and it classifies strains into PFGEtypes USA100-1200.

4. Macrorestriction pattern analysis: analysis of restriction polymorphisms of the whole chromosome.

5. Multilocus VNTR analysis (MLVA): analysis of polymorphisms in chromosomal VNTR elements.

\section{GLOBAL VIEW}

There are around 20 distinct genetic lineages of MRSA around the world. The 5 global predominant are ST1-IV (WA-1, USA400); ST8-IV (USA 300), ST30-IV (South West Pacific clone), St 59-V (Taiwan clone), ST80-IV (European clone). There are 2 strains classified as pandemic: ST8-IV (USA300 lineage); ST30-IV (South West Pacific clone SWP) (Figure 2). $4,6,13$

Figure 2. Global distribution of MRSA strains.

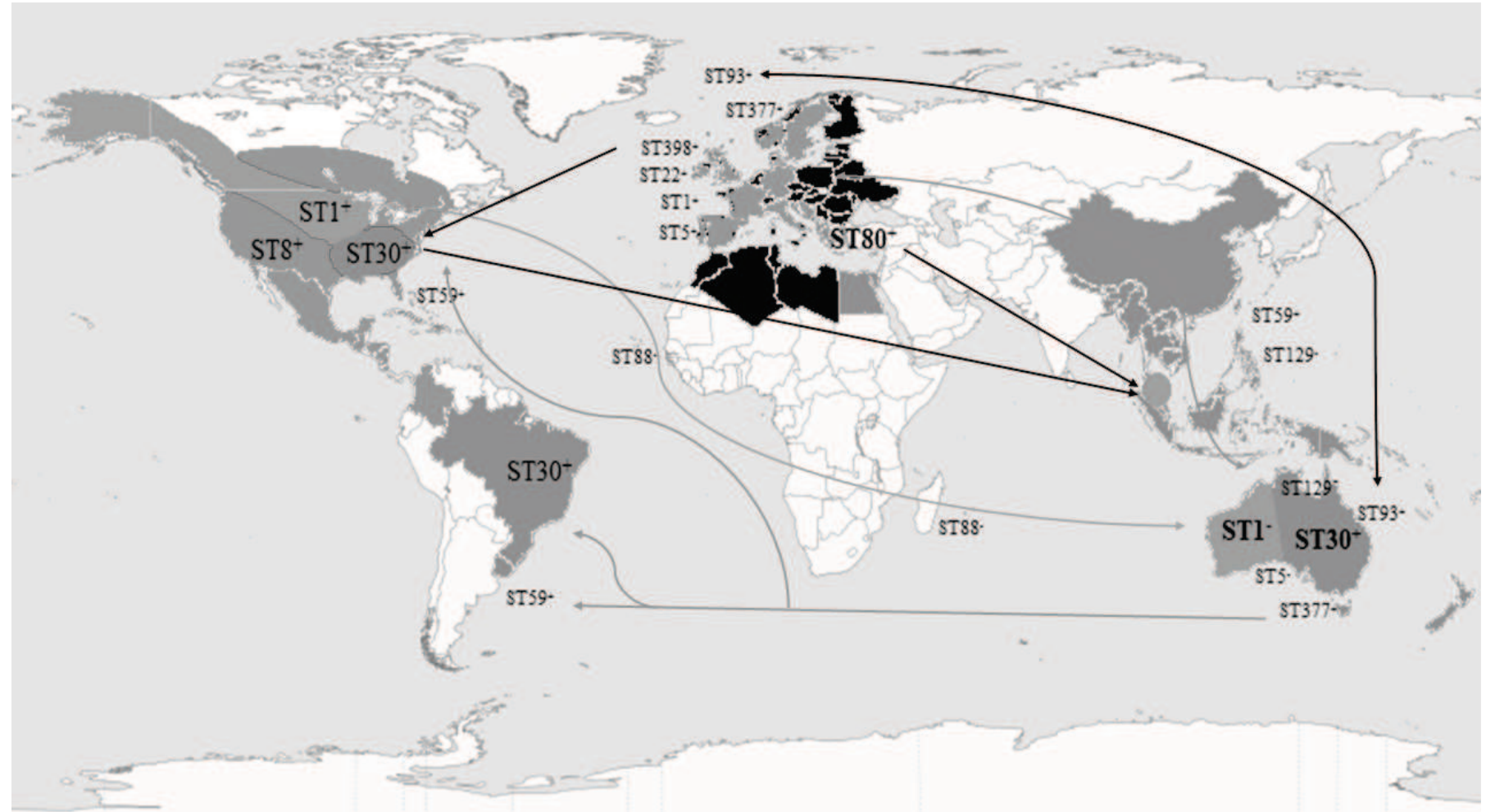

Source: Prepared by the author. 
The most prevalent area of infection by MRSA is the EUA. The most prevalent strain is "USA300" lineage. A reasonable explanation to this condition are the different social panoramas between EUA and Europe. The USA infection panorama is homogeneous with a predominant lineage, while in Europe there is a heterogeneous panorama once none lineage predominates. However, ST80-IV is the most common lineage in Europe. ${ }^{4,13}$ The prevalence of MRSA worldwide could be divided in 3 main zones: Americas and Asia (highest prevalence), East Europe (intermediate prevalence) and West Europe (low prevalence). , $, 6,13^{-13}$

The decline of prevalence of MRSA worldwide could be divided in 3 main zones: Americas and Asia (low decline), East Europe (intermediate decline) and West Europe (high decline). This data contribute to a social analysis of the infection. Nations with more precarious health systems are less likely to fight and contain MRSA infection, while developed nations where MRSA is combated quickly and effectively. ${ }^{4,6,13}$

In South America, the 2 predominant HA-MRSA clones are: Brazilian clone (sequence type ST239) - related to Russian clones, which bears the SCCmecIII (MRSA0ST239-III), and the Chilean/ Cordobes clone (MRSA-ST5-I). However, USA300 has disseminated through Latin America as the main cause of CA-MRSA. In Uruguay and Brazil, USA 300 CA-MRSA isolates have been reported that display distinct genetic characteristics (MRSA-ST30-IVc). Interestingly, this strain, recently dubbed "USA300-LV" (Latin America Variant) appears to be a separate lineage which may be distinguished from the North America strain (USA300-0114) by various molecular features including SCCmec subtype (IVc) and absence of ACME. The dissemination of CAMRSA isolates in South America hospital environments was first reported in Colombia in 2009. In the Andean countries (Colombia, Venezuela, Peru, and Ecuador), the CA-MRSA isolates present similar characteristics to the USA300 clone, including MRSA-ST8-IVc-E, PVL positivity, and multisusceptibility. ${ }^{10,14}$

In the USA, the predominant CA-MRSA clone is ST8+ SCCmecIVa - PVL positive or USA300. Meanwhile, a few years ago USA400 was the predominant clone, but after a clonal expansion it became USA300. ST1+ or USA400 is still predominant in northern areas of America (e.g. Alaska and Canada), while USA300 is predominant in USA itself. USA300 lineage cause the majority of complicated SSTI worldwide, it has a high mortality and high treatment failures and could be considered pandemic and hypervirulent.

The fast emergence of USA lineage comes from the combination of 3 main elements: newly acquired virulence genes (gene acquisition), altered expression of common virulence determinants (altered gene regulation), and alterations in protein sequences that increase fitness (sequence polymorphisms - protein sequence divergence). However, it is likely that no single explanation can suffice, and that MRSA represents a continuously emergent phenomenon driven by multi-factorial interactions between the classic triad of host, pathogen, and environment. ${ }^{3}$

Different from the USA, MRSA infections are less prevalent and more heterogeneous in Europe. In 2003, the first European case was reported in Greece (country where MRSA infections are more prevalent in Europe). The most common clone in Europe is ST80+, but in certain areas there are other clones. For example, ST22-IV or EMRSA-15 in UK; ST239/spa3 (t037)/ SCCmecIII, ST239/spa351(t030)/SCCmec III and ST8/spa1 (t008)/ SCCmecIV in Russia. The Russian clones are divided according to geographic areas: ST239 is more prevalent in European and Eastern Russia, while ST8 is more prevalent in Siberia Russia. The clones present in Siberia Russia are very similar to Brazilian clones. It could be possible because of migration of strains and transference of genetic material. ${ }^{15}$

In Asia, the 2 predominant clones are ST59- IV (USA1000) and ST59-V (Taiwan clone). However, Asia is a very diverse region with many different clone: ST22-IV \& ST772-V in India; ST59-V in Taiwan, Vietnam and China; ST72+ in Korea; ST121+ and ST834+ in Cambodia; and ST30+ in South Pacifica, Australia and Russia. It also common to Asian strains be PVL negative. ${ }^{2,4,13,16}$ In Japan, the most prevalent clone is the Japanese ST8 SCCmecIVl (designatedST8 CA/J). The first case was reported in 2003. The Japanese clone is very similar to the USA clone ST8 SCCmecIVa (USA300), but with marked diversity in accessory genes. For example, ST8 CA/J possessed enhanced cytolitic peptide genes, but lacked the PVL phage and ACME, unlike USA300. From a genetic point of view, ST8 CA/J is a geographic variant of ST8 CA-MRSA, which is one of the most disseminated lineages. However, ST8 CA/J - PVL negative is the most common clone some PVL positive strains were identified in Japan like: ST6 and ST59. 2, 4, 13, 16

Negative point: MRSA classification is not clear whether the incidence of CA-MRSA infections reported in many parts of the world is adequately reflected or influenced by less stringent testing and reporting measure. . $^{2,413,16}$

\section{TREATMENT}

Until the last century, there was no treatment to $S$. aureus infection. After antibiotics discovery, this reality has changed a lot. Penicillin was an inexpensive, non-toxic and high effective drug used against Staphylococcus in the first years. However, bacteria became resistant and new and more potent drugs were developed.

\section{a) Antibiotics}

Nowadays, SSTI are treated empirically based on antibiotic guidelines. Except abscesses, which, according to literature, are treated with incision and drainage. ${ }^{1}$

In less severe cases, MRSA infections are conventionally treated with oral antibiotics. Clindamycin oral is the gold pattern treatment. Also, tetracyclines (doxycycline, minocycline) could be used, but doctors should take care of side effects. Possible adjunct drugs are Rifampicin and Fusidic 
Acid, but they should be never used alone. ${ }^{1}$

Linezolid (Oxazolidinone) is an expensive drug reserved for serious infections (comple STTI and MRSA pneumonia) when oral drugs are not an option. Doctors should take care of toxicity: myelosuppression, peripheral neuropathy, optic neuritis and lactic acidosis.

In severe cases (e.g. bacteraemia), MRSA infections are conventionally treated with intravenous antibiotics. Vancomycin IV is the gold pattern treatment. Doctors should take care of nephrotoxicity with high doses. ${ }^{1}$

Despite the vast current therapeutic arsenal, multiresistant strains are emerging. Resulting in the need for new and more effective drugs. ${ }^{1}$

\section{b) Experimental drugs}

These drugs are rapidly effective, but they are related to hypersensibility cases. They are divided in 3 subgroups: ${ }^{1}$

1. Glycopeptides derivates: telavancin, dolbavancin, ontanvancin;

2. Anti-MRSA B-lactam: ceftaroline, ceftabiprole;

3. Derivates of Vancomycin: telavancin, dalbavancin.

c) Vaccine

There are not any clinically approved vaccine. The researches focus in 2 vaccine mechanisms: enhance opsonophagocytosis or antitoxin. The main reason to vaccine failure is the fact that mostresearches focus on vaccines based on opsonophagocytosis process. But the bacteria has a neutrophil lysis mechanism after being engulfed which makes phagocytosis ineffective. ${ }^{1}$

\section{d) Immunotherapy}

Passive immunization with antibodies to sequester main

\section{REFERENCES}

1. DeLeo FR, Otto M, Kreiswirth BN, Chambers HF. Communityassociated meticillin-resistant Staphylococcus aureus. Lancet. 2010;375(9725):1557-68.

2. Kawaguchiya M, Urushibara N, Kuwahara O, Ito M, Mise K, Kobayashi N. Molecular characteristics of community-acquired methicillin-resistant Staphylococcus aureus in Hokkaido, northern main island of Japan: identification of sequence types 6 and 59 Panton-Valentine leucocidin-positive community-acquired methicillin-resistant Staphylococcus aureus. Microb Drug Resist. 2011;17(2):241-50.

3. Thurlow LR, Joshi GS, Richardson AR. Virulence strategies of the dominant USA300 lineage of community-associated methicillinresistant Staphylococcus aureus (CA-MRSA). FEMS Immunol Med Microbiol. 2012;65(1):5-22.

4. Mediavilla JR, Chen L, Mathema B, Kreiswirth BN. Global epidemiology of community-associated methicillin resistant virulence determinants of $S$. aureus may represent a valuable alternative to active immunization in the future, but it requires more research. Example: Monoclonal alpha - toxin. ${ }^{1}$

\section{FINAL CONSIDERATIONS}

MRSA is a seriously health problem across the globe because: lack of knowledge on the genetic control of the bacteria, its high mortality and its multidrug resistance. Thus, in the next years, researchers should focus on better understand the bacteria-derived factors that participate in enhanced MRSA pathogenesis \& host susceptibility; improve tools for an early diagnosis; enhance preventative and therapeutic modalities. Otherwise, we will face an increased number of infections, new antibiotic resistance and low positive clinical outcomes. Work on developing research for better understanding of the genetic mechanisms involved will bring the possibility of creating vaccines or immunotherapies able to contain the bacteria more effective and specific way.

However, new challenges remain emerging. For instance: drug resistance to the most potent antibiotics actually used (e.g. vancomycin, daptomycin, linezolid); interactions between HA- MRSA, CA -MRSA, LA -MRSA resulting in possible new and more resistant strains; spread by new reservoirs; pandemic clones and not genotyped strains. Thus, scientist will need to continuously develop new methods to identify markers of hypervirulence, transmissibility and persistence; and new/more effective treatments.

\section{ACKNOWLEDGEMENTS}

I would like to thank Dr Cristiane Cunha for her support during my Microbiology monitoring and in this thesis process. I would like to thank Dr Mal Horsburgh and Dr Viv Dillon for their extraordinary support during this year abroad and in this thesis process. Also, this project would have been impossible without the financial support of the Program Science without Borders-UK (SwB-UK) and the National Research Council (CNPq-BR).

Staphylococcus aureus (CA-MRSA). Curr Opin Microbiol. 2012;15(5):588-95.

5. Skov RL, Jensen KS. Community-associated meticillin-resistant Staphylococcus aureus as a cause of hospital-acquired infections. J Hosp Infect. 2009;73(4):364-70.

6. Witte W. Community-acquired methicillin-resistant Staphylococcus aureus: what do we need to know? Clin Microbiol Infect. 2009;15 Supl 7:17-25.

7. Aguilar JL, Varshney AK, Wang X, Stanford L, Scharff M, Fries BC. Detection and measurement of staphylococcal enterotoxin-like K (SEl-K) secretion by Staphylococcus aureus clinical isolates. J Clin Microbiol. 2014;52(7):2536-43.

8. Alonzo F 3rd, Torres VJ. The bicomponent pore-forming leucocidins of Staphylococcus aureus. Microbiol Mol Biol Rev. 2014;78(2):199-230. 
9. Kobayashi SD, DeLeo FR. An update on community-associated MRSA virulence. Curr Opin Pharmacol. 2009;9(5):545-51.

10. Otto M. Basis of virulence in community-associated methicillinresistant Staphylococcus aureus. Annu Rev Microbiol. 2010;64:14362.

11. Elston JW, Barlow GD. Community-associated MRSA in the United Kingdom. J Infect. 2009;59(3):149-55.

12. Otter JA, French GL. Community-associated meticillin-resistant Staphylococcus aureus: the case for a genotypic definition. J Hosp Infect. 2012;81(3):143-8.

13. Stefani S, Chung DR, Lindsay JA, Friedrich AW, Kearns AM, Westh H, et al. Meticillin-resistant Staphylococcus aureus (MRSA): global epidemiology and harmonisation of typing methods. Int $\mathrm{J}$ Antimicrob Agents. 2012;39(4):273-82.
14. Portillo BC, Moreno JE, Yomayusa N, Alvarez CA, Cardozo $\mathrm{BE}$, Perez JA, et al. Molecular epidemiology and characterization of virulence genes of community-acquired and hospital-acquired methicillin-resistant Staphylococcus aureus isolates in Colombia. Int J Infect Dis. 2013;17(9):e744-9.

15. Khokhlova OE, Hung WC, Wan TW, Iwao Y, Takano T, Higuchi $\mathrm{W}$, et al. Healthcare- and community-sssociated methicillin-resistant Staphylococcus aureus (MRSA) and fatal pneumonia with pediatric deaths in Krasnoyarsk, Siberian Russia: unique MRSA's multiple virulence factors, genome, and stepwise evolution. PLoS One. 2015;10(6):e0128017.

16. Iwao Y, Ishii R, Tomita Y, Shibuya Y, Takano T, Hung WC, et al. The emerging ST8 methicillin-resistant Staphylococcus aureus clone in the community in Japan: associated infections, genetic diversity, and comparative genomics. J Infect Chemother. 2012;18(2):228-40.

\section{Como citar:}

Farias AL, Frota CC. Staphylococcus aureus (MRSA and CA-MRSA strains) in South America: comparative review to emergence of strains in North America and worldwide. Rev Med UFC. 2015 jul-dez;55(2):39-45. 